\section{SOFRIMENTO CRÔNICO: PERCEPÇÃO DE MÃES DE CRIANÇAS DEPENDENTES DE VENTILAÇÃO MECÂNICA}

\author{
Chronic suffering: mother's perception of children dependent \\ on mechanical ventilation
}
Sufrimiento crónico: la percepción de madres de niños dependientes de la ventilación mecánica

\section{RESUMO}

Objetivo: Conhecer a percepção das mães sobre as principais dificuldades na assistência a uma criança com necessidades especiais, dependente de ventilação mecânica. Métodos: Pesquisa qualitativa, desenvolvida de agosto a novembro de 2013 no Hospital Dr. Waldemar Alcântara, em Fortaleza-CE. Os informantes foram sete mães de crianças sob ventilação mecânica. A coleta de dados deu-se através de questionários sociodemográficos e questões norteadoras, das quais emergiram categorias temáticas, analisadas pela análise de conteúdo, sendo os dados discutidos pela literatura pertinente. Resultados: A média das idades maternas variou de 18 a 36 anos. Seis eram casadas ou viviam união estável. O nível de escolaridade variou de analfabeta ao segundo grau completo. A renda familiar foi de no máximo um salário mínimo. As mães mencionaram angústia e medo diante do impacto inicial do diagnóstico, com pouca compreensão da linguagem biomédica e muitos questionamentos durante todo o período após o diagnóstico e durante a internação hospitalar. Conclusão: As dificuldades envolvem aspectos relacionados ao abandono familiar, ao distanciamento dos demais filhos em detrimento do cuidado ao filho deficiente, ao obstáculo em se relacionar socialmente e acerca do prognóstico e cuidados com seu filho. $\mathrm{O}$ ambiente hospitalar gera repercussões psicológicas diante da expectativa e da falta de esperança em relação à cura do filho, sabendo que este poderá ir a óbito. Os profissionais de saúde podem favorecer transformações incríveis, gerando um novo "cuidar", mais amplo e humanizado, facilitando a recuperação/reestruturação familiar diante desse novo universo.

Descritores: Fisioterapia; Criança Hospitalizada; Humanização da assistência; Relações Mãe-Filho; Ventilação Pulmonar.

\section{ABSTRACT}

Objective: To know the mothers' perception of the main difficulties in the care of children with special needs dependent on mechanical ventilation. Methods: A qualitative research conducted from August to November 2013 at the Dr. Waldemar Alcântara Hospital in Fortaleza, CE. Respondents were seven mothers of children under mechanical ventilation. Data were collected using sociodemographic questionnaires and guiding questions, from which emerged thematic categories that underwent content analysis, with data being discussed in the light of the relevant literature. Results: The average age of mothers ranged 18-36 years. Six were married or had formed a common-law marriage. Education level ranged from illiteracy to complete secondary education. Family income was up to one minimum wage. Mothers reported anguish and fear regarding the initial impact of the diagnosis, with little understanding of the biomedical language and a lot of questions during the whole period after diagnosis and during hospitalization. Conclusion: Difficulties involve aspects related to family abandonment, the distancing from the other children at the expense of the care of the disable child, the difficulty in engaging in social relationships, and the prognosis and care of their child. The hospital environment generates psychological repercussions on the expectation and hopelessness regarding the cure of their child, as they know they might die. Healthcare professionals can favor incredible transformations, generating a new "care",
Artigo Original
1) Universidade de Fortaleza UNIFOR - Fortaleza (CE) - Brasil
Recebido em: 23/04/2015 Revisado em: 25/05/2015 Aceito em: 10/06/2015 
broader and humanized, facilitating the recovery/restructuring of the family within this new universe.

Descriptors: Physical Therapy; Hospitalized Child; Humanization of assistance; Mother-Child Relations; Pulmonary Ventilation.

\section{RESUMEN}

Objetivo: Conocer la percepción de madres sobre las principales dificultades de la asistencia de un niño con necesidades especiales, dependiente de la ventilación mecánica. Métodos: Investigación cualitativa desarrollada entre agosto y noviembre de 2013 en el Hospital Dr. Waldemar Alcântara de FortalezaCE. Los informantes fueron siete madres de niños en ventilación mecánica. La recogida de datos se dio a través de cuestionarios sociodemograficos y preguntas norteadoras de las cuales surgieron las categorías temáticas analizadas por el análisis de contenido con los datos discutidos con la literatura pertinente. Resultados: La media de las edades maternas vario entre 18 y 36 años. Seis eran casadas o tenían una unión estable de pareja. El nivel de escolaridad varió de analfabeta hasta la educación secundaria completa. La renta familiar era como mucho de un sueldo mínimo. Las madres relataron la angustia y el miedo delante el impacto inicial del diagnóstico con poca comprensión del lenguaje biomédico y muchas preguntas durante todo el periodo tras el diagnóstico y durante el ingreso hospitalario. Conclusión: Las dificultades incluyen los aspectos relacionados al abandono familiar, a la distancia de los otros hijos en detrimento del cuidado del hijo discapacitado, del obstáculo de relacionarse socialmente y sobre el pronóstico y los cuidados con su hijo. El ambiente hospitalario genera repercusiones psicológicas frente la expectativa y la falta de esperanza respecto la cura del hijo, consciente que el mismo podrá morir. Los profesionales de la salud pueden favorecer transformaciones increibles generando un nuevo "cuidar", más amplio y humanizado que facilite la recuperación/reestructuración familiar frente este nuevo universo.

Descriptores: Fisioterapia; Niño Hospitalizado; Humanización de la Atención; Relaciones Madre-Hijo; Ventilación Pulmonar.

\section{INTRODUÇÃO}

O desenvolvimento infantil motor é classificado em típico ou atípico, remetendo-se ao processo de maturação e desenvolvimento do sistema nervoso central - $\mathrm{SNC}^{(1)}$. Este apresenta evolução intensa, que se inicia na fase fetal (por volta da $10^{\mathrm{a}}$ semana gestacional) com a mielinização nas raízes espinhais, permitindo uma atividade motora reflexa fetal, finalizando quando alcança seu pico de maturidade, já na infância ${ }^{(2)}$. Diversas patologias podem afetar o desenvolvimento neuropsicomotor na infância, como a paralisia cerebral (PC), inúmeras síndromes, atrofia muscular espinhal, asfixias neonatais e malformações congênitas, podendo gerar sequelas em crianças e torná- las susceptíveis a cuidados especiais de uma equipe multidisciplinar em unidades hospitalares ${ }^{(1,2)}$. Essas patologias são crônicas e incapacitantes, sendo necessário o acompanhamento por equipes especializadas, que adotem medidas de suporte, como a fisioterapia respiratória, que ajuda a mobilizar as secreções e a diminuir a incidência de infecções respiratórias, podendo necessitar do uso de vias aéreas artificiais, as quais podem estar associadas a um suporte ventilatório prolongado, classificado como Ventilação Mecânica Invasiva (VMI) ${ }^{(2,3)}$.

O procedimento inicial para uma criança que necessita de ventilação mecânica é a intubação traqueal, podendo ser prolongado e necessitar da indicação de traqueostomia, dependendo da doença subjacente e da idade da criança. A ventilação mecânica (VM) é um dos recursos terapêuticos mais frequentemente utilizados nas unidades de terapia intensiva neonatal e pediátrica ${ }^{(3)}$.

Quando a equipe médica opta pelo procedimento cirúrgico da traqueostomia na criança, essa decisão é complexa e depende de vários fatores, incluindo gravidade da obstrução da via aérea, tempo de intubação e sua condição clínica. A traqueostomia pode ser indicada também para facilitar a aspiração de secreções das vias aéreas de crianças entubadas por um longo período ${ }^{(2,3)}$.

Crianças com déficits neurológicos importantes podem apresentar padrões respiratórios patológicos e evoluir para uma insuficiência respiratória devido à dificuldade de manter a relação ventilação/perfusão ${ }^{(3)}$. A insuficiência respiratória aguda (IRpA) é definida como a incapacidade do sistema respiratório de obter oxigênio $\left(\mathrm{O}_{2}\right)$ para suprir as necessidades teciduais e de eliminar dióxido de carbono $\left(\mathrm{CO}_{2}\right)$ proveniente do metabolismo celular ${ }^{(4)}$.

Em patologias com disfunções neuromusculares, a insuficiência respiratória é resultado de um déficit na função ventilatória, pois a fraqueza da musculatura respiratória leva à alteração na mecânica respiratória, seguida de episódios de hipoventilação alveolar. Em decorrência desse processo, instala-se um quadro caracterizado por hipercapnia crônica e hipoxemia secundária à elevação da pressão parcial de dióxido de carbono no sangue arterial $\left(\mathrm{PaCO}_{2}\right)^{(5)}$.

O suporte ventilatório foi um grande avanço terapêutico nas últimas décadas, sendo desenvolvidas várias técnicas ventilatórias e assim associando-se à melhora da sobrevida de pacientes portadores de insuficiência respiratória de várias etiologias ${ }^{(5,6)}$.

A longa permanência no ambiente hospitalar, principalmente emuma Unidade de Cuidados Especiais, pode expor a criança e a mãe/cuidador(a) a infecções hospitalares e transtornos psicológicos ${ }^{(7)}$. Para a família, especialmente para a figura materna, a visão do desconhecido, num cenário composto por muitas luzes, aparelhos, profissionais 
especializados e estimulação sonora com muitos alarmes e ruídos, produz angústia, incerteza e insegurança em relação ao prognóstico do seu filho ${ }^{(8)}$.

A hora do diagnóstico para a família é a mais difícil, porém, viver esse momento é importante para elaborar a realidade atual, ressignificar a sua experiência com a chegada de uma criança que foge aos padrões de algo desejado e esperado em seu imaginário, e buscar a compreensão de como lidar com essa criança com doença crônica. Nesse caso, o papel de uma equipe multidisciplinar no primeiro momento do contato dos pais com a doença é de grande importância, devendo-se adotar uma postura de acolhimento e diálogo para gerar um amadurecimento diante da situação de aceitação da doença, resignando-se a um novo modo de vida ${ }^{(9)}$.

Assim, o vínculo mãe-filho tem sido objeto de estudos científicos, confirmando os benefícios fisiológicos e psicossociais tanto para a saúde da mãe quanto para a criança. Esse contato acalma a criança, e a mãe entra em sintonia proporcionada por esse momento, auxiliando na estabilização sanguínea, nos batimentos cardíacos e na respiração da criança ${ }^{(10)}$. As pesquisas científicas demonstram que, além da busca por uma assistência que fortifique a presença da mãe junto ao filho e a legitimação conferida pelo Estatuto da Criança e do Adolescente (ECA), têm sido criadas estratégias que facilitam a permanência da mãe junto ao filho nas situações em que são necessários os cuidados hospitalares. Oferecer um atendimento humanizado implica utilizar tecnologias além daquelas contidas nos equipamentos, e o cuidado da mãe é uma metodologia que deve ser incorporada como parte da assistência ao filho ${ }^{(11)}$.

Sendo assim, ao desenvolver esta pesquisa, objetivouse conhecer a percepção das mães sobre as principais dificuldades na assistência a uma criança com necessidades especiais, dependentes de ventilação mecânica.

\section{MÉTODOS}

A pesquisa seguiu uma metodologia do tipo qualitativa, desenvolvida de agosto a novembro de 2013 no Hospital Geral Dr. Waldemar Alcântara (HGWA), localizado em Fortaleza-CE, classificado como hospital de nível secundário dentro da rede pública de saúde. Realizou-se o estudo na Unidade de Cuidados Especiais Pediátricos (UCE PED), que conta com oito leitos. Nessa unidade, todas as crianças possuem enfermidades crônicas, necessitando de vias aéreas artificiais (traqueóstomo) e/ou suporte ventilatório. A unidade possui uma equipe multidisciplinar composta por médicos, fisioterapeutas, enfermeiros, fonoaudiólogos e auxiliares de enfermagem.
Participaram do estudo mães de crianças sob ventilação mecânica, internadas na Unidade de Cuidados Especiais Pediátrica. Foram incluídas no estudo mães acima de 18 anos, com filhos internados nessa unidade e que aceitaram participar da pesquisa, sendo excluídas as mães com deficiência auditiva grave que inviabilizasse a coleta de dados.

Inicialmente, coletaram-se as informações maternas num questionário sociodemográfico composto pelos seguintes dados: idade, renda familiar, escolaridade, estado civil, ocupação, número de filhos, número de gestações e número de abortos.

A partir de então, iniciou-se entrevista individual, num local reservado (sala da fisioterapia pediátrica), garantindo a confidencialidade das informações, utilizando perguntas norteadoras e estimulando a narrativa livre dessas mães acerca da sua experiência vivenciada, sem interferência do entrevistador, que se manteve em postura neutra. A narrativa foi captada por um gravador de voz, durante um prazo de tempo livre.

As perguntas norteadoras aplicadas na entrevista foram: "Descreva como você se sentiu quando soube que seu filho era portador de cuidados especiais. Descreva o que a senhora sente mais dificuldade, pela situação do seu filho(a), em relação à sua família e à sociedade. O que a senhora compreende desse aparelho que é utilizado para auxiliar na respiração do seu filho? A senhora lembra qual profissional the informou do diagnóstico? Como ele informou a noticia? Em sua opinião, os profissionais da saúde estão preparados para lidar com esse momento delicado de dar esse tipo de notícia às famílias?"

Após a coleta de dados, as entrevistas foram transcritas integralmente e de forma fidedigna, seguida dos dados e análise de conteúdo ${ }^{(12)}$, sendo discutidos baseados na literatura pertinente ao assunto.

A análise de conteúdo ${ }^{(12)}$ possui fases que organizam-se em torno de três polos: 1. A pré-análise; 2. A exploração do material; e 3 . O tratamento dos resultados: a inferência e a interpretação. A partir da transcrição das entrevistas, agruparam-se os conteúdos por similaridades de significados e desvelaram-se cinco categorias temáticas: "Arrasada": a dor diante do diagnóstico; Preparação profissional diante da notícia; O cuidado com o filho especial; O contexto familiar e social num sofrimento crônico; e "Aquele aparelho": compreensão acerca da ventilação mecânica.

A pesquisa respeitou os preceitos éticos regidos pela Resolução n ${ }^{\circ}$. 466/2012 do Conselho Nacional de Saúde ${ }^{(13)}$ e foi aprovada pelo Comitê de Ética da Universidade de Fortaleza, com número do parecer 573.532, em 24 de março de 2014. 
Realizou-se a referida pesquisa com sete mães de um total de oito mães do setor, pois uma estava ausente durante o período da coleta. Foram utilizadas siglas com iniciais $\mathrm{M}$ e numeração arábica (de 1 a 7) para identificar as participantes.

\section{RESULTADOS E DISCUSSÃO}

Após a coleta das informações do questionário sociodemográfico, utilizou-se a descrição desses dados para identificar o contexto social e demográfico vivenciado por essas mães, para permitir posteriormente a imersão na subjetividade de cada narrativa, através das categorias temáticas.

A média das idades maternas variou de 18 a 36 anos. Seis eram casadas ou viviam união estável e uma era solteira pelo abandono do companheiro quando soube do diagnóstico do filho. O nível de escolaridade variou de analfabeta ao segundo grau completo. A renda familiar foi de no máximo um salário mínimo. Antes de se dedicarem exclusivamente aos cuidados dos filhos, seis delas trabalhavam. Todas as mães possuíam outros filhos, sendo que três mães possuíam dois filhos. Quanto a terem sofrido abortos, apenas duas mães relataram essa experiência.

\section{"Arrasada": a dor diante do diagnóstico}

Essa categoria leva à compreensão da sensibilidade materna como um foco central do processo interativo entre mãe-filho em etapas iniciais do desenvolvimento, favorecendo a formação do vínculo entre eles, que não se separa do contexto sociocultural no qual a díade mãe-filho está inserida. A percepção inicial de dependência total da criança deficiente gera nas mães sentimentos antagônicos de amor/ódio, aceitação/rejeição ${ }^{(14)}$.

A gravidez nunca é apenas um processo fisiológico e somático. A mãe sonha com o seu filho, formando uma imagem consciente e inconsciente do corpo e personalidade da criança, de acordo com seus desejos e vivências, criando expectativas. Sendo assim, o nascimento de uma criança com necessidades especiais pode representar para os pais e familiares um evento desastroso, com ruptura de significados simbólicos do nascimento, gerando sentimentos de medo e frustração $0^{(15)}$.

No momento da notícia, as mães relataram profunda tristeza frente à ausência da satisfação do desejo do filho idealizado. As falas revelam experiências pungentes de mães que se mostram absolutamente confusas por não saberem lidar com uma situação inesperada e considerada extremamente difícil.

Uma entrevistada, com idade de 27 anos, evidencia sua dedicação integral aos cuidados da filha deficiente e seus sentimentos em relação à vivência atual:
"[...] Muito mal, porque ela não era assim; era uma menina sadia. Andava, brincava, estudava, e foi descoberto assim, de uma hora pra outra, que minha filha tinha essa doença. Ai ela ficou várias vezes internada. Eu deixei de trabalhar, não pude mais trabalhar pra cuidar dela. Ai agora ela depende de mim. Agora eu não posso trabalhar mais, fico só com ela." (M2)

Em seu pungente discurso, outra mãe evidencia sua indignação ao que ela classifica como "erro médico":

"Me senti mal, né... porque eu não esperava. Na hora eu fiquei triste, né, porque eu sei que foi por um erro médico. Porque o meu filho, que era pra ser sadio, ter sido uma criança perfeita, normal, por conta da intercorrência na hora do parto, ele teve paralisia cerebral, teve asfixia, e agora ele é uma criança especial devido a isso." (M3)

A angústia perpassa nas falas das mães que lastimam o fato de os filhos não terem nascido saudáveis. Entretanto, pauta-se a questão da espiritualidade como forma de aceitar essa tarefa, a qual, segundo o discurso a seguir, não deve ser discutida, e sim acatada, pois foi determinada por um ser superior ${ }^{(16)}$.

Uma jovem mãe de 22 anos, com lágrimas nos olhos, descreve como se sentiu no momento do diagnóstico do filho:

"Ah, fiquei arrasada. Não sei explicar assim muito bem, sabe, mas quando disseram pra mim que ele ia ser especialzinho, que ele tinha essa síndrome, né, não sei nem explicar. Fiquei tão arrasada, tão arrasada, com medo de perder ele também. Não sei, né, só Deus sabe, mas eu sei que vou perder ele mesmo." (M4)

A presença da espiritualidade como aspecto relacionado à qualidade de vida já é algo discutido pela Organização Mundial de Saúde (OMS). Pode-se conceituar a espiritualidade como algo relacionado a uma pessoa com força de vida não material ou com um poder maior. Não é preciso uma explicação racional para comprovar a sua existência. A dimensão espiritual do cuidado a essas crianças surge como modo de enfrentamento das adversidades, de desesperança velada e da impossibilidade da cura ${ }^{(17)}$.

\section{Preparação profissional diante da notícia}

Essa categoria evidencia a reação inicial diante do diagnóstico, que pode ser influenciada pela maneira como a notícia é comunicada aos pais. Esta deve ser transmitida da maneira menos traumática possível. Segundo o Código de Ética Médica, a responsabilidade de transmitir o diagnóstico de uma doença é do médico, porém, a equipe multiprofissional deve viabilizar momentos para esclarecer dúvidas $^{(18)}$. 
Os profissionais da saúde devem ser cautelosos ao se expressar com indivíduos em situações de vulnerabilidade, sejam físicas ou emocionais. Não devem, portanto, usar o termo "cura" em condições crônicas, para não gerar expectativas diante de um propósito não alcançado, mas as crianças devem ser vistas como seres com grande potencial de melhora ${ }^{(19)}$.

Em seu discurso, uma entrevistada evidencia a falta de diálogo e compreensão com os profissionais de saúde:

"Ele só disse que o menino tinha um problemazinho da cabeça, de malformação do cérebro, que não estava conseguindo respirar sozinho. Toda vez eles explicam, só que eles explicam de uma maneira diferente, né, da gente entender.” (M1)

Apesar de a antropologia vir auxiliando no entendimento desses fenômenos cada vez com mais clareza, o modelo biomédico é ainda brutalmente hegemônico, levando a uma visão reducionista da doença, vista como processo exclusivamente biológico ${ }^{(20)}$. O modelo biomédico é opressor em relação aos conceitos e percepção da população $^{(21)}$, e evidencia sua impossibilidade de oferecer respostas satisfatórias para muitos problemas, sobretudo para os componentes psicológicos ou subjetivos que acompanham qualquer doença. Tal modelo estimula os profissionais de saúde a aderirem a um comportamento extremamente cartesiano na separação entre o observador e o observado, desconsiderando o saber popular, as crenças religiosas e o contexto cultural e social em que o indivíduo está inserido ${ }^{(21)}$.

Outra participante do estudo discorre acerca da falta de preparo profissional e do sofrimento gerado por esse "despreparo":

"Ah, foi assim, de uma hora pra outra, sabe. A única coisa que eu perguntei a ela foi sobre os dedinhos dele. Ai de repente ela começou: 'Não, mãezinha, isso aí vamos deixar para o último caso, por causa que ele tem uma síndrome muito grave. Eu vou logo avisando que o seu filho não tem muito tempo de vida e vai morrer a qualquer momento.' Falou assim, de uma vez. Nossa, naquela hora o chão se abriu, porque foi de uma vez. Ela nem preparou." (M4)

A boa relação profissional-paciente é um dos fatores mais importantes para o sucesso terapêutico. Esse relacionamento é capaz de gerar uma mudança de atitude no paciente em relação ao sofrimento vivido. Uma relação baseada na troca mútua de confiança, empatia e afetividade pode desencadear em ambos uma mudança profunda ${ }^{(22)}$.

Paciente e profissional da saúde são sujeitos de um contexto pessoal, familiar e social próprios, cujas necessidades pessoais e sociais em interação no decorrer de um atendimento ou experiência terapêutica são diversificadas e precisam ser respeitadas, mediadas e negociadas por ambos ${ }^{(23)}$.

\section{O cuidado com o filho especial}

Essa categoria remete à questão de que a mulher/ mãe é, culturalmente, a principal cuidadora no âmbito doméstico e tem cada vez mais responsabilidades, sentindo-se pressionada a tomar conta da casa e dos filhos, principalmente quando estes são deficientes. Apesar de a condição da criança atingir todo o grupo familiar, geralmente a figura materna é a mais envolvida no cuidado ao filho. O cuidador passa a viver, portanto, em função do filho, estando suas ações voltadas primeiramente às necessidades da crianç ${ }^{(24)}$. Falar de cuidado de saúde atribui ao termo um sentido já consagrado no senso comum, o de um conjunto de procedimentos tecnicamente orientados para o bom êxito de certo tratamento. Porém, cuidado, do latim cura, em uma forma mais antiga, coesa, era usado nas relações de amor e amizade, expressando uma atitude de desvelo e preocupação ${ }^{(25)}$.

Uma participante de 20 anos de idade, mãe de dois filhos, enfatiza seus sentimentos no cuidado com o filho:

"[...] Jamais nós, como mãe, queremos ver nossos filhos daquele jeito, né? Mas como a gente sabe que é pro próprio bem, a gente tem que fazer. Vai fazer um ano que ele está traquestomizado, ai precisa de ser aspirado. Eu não me acostumei ainda com a vida do meu filho. Me sinto muito mal mesmo quando eu tenho que aspirar ele [...] Sinto mais dificuldade assim é na hora do banho, né, que a gente tem que banhar ele deitado. É um processo muito grande [...]" (M6)

$\mathrm{Na}$ perspectiva da pessoa enferma ou de entes próximos, a doença traz um impacto no fluxo da sua vida cotidiana, alterando radicalmente seu mundo, colocando-o numa situação de desordem e ruptura ${ }^{(26)}$. A vulnerabilidade dos cuidadores no ambiente hospitalar, representada por alterações fisiológicas, emocionais e cognitivas, advém do impacto dos diversos estressores existentes nesse ambiente, isto é, do excesso de trabalho, do contato constante com o sofrimento do outro e da imprevisibilidade do estado geral dos pacientes ${ }^{(27)}$.

Portanto, na tentativa de enfrentar essa dificuldade, as mães tornam-se dedicadas exclusivamente ao cuidado dos filhos, em detrimento da execução de suas atividades habituais. O cuidar materno também é marcado pela renúncia. A renúncia de si em prol do outro, o filho ${ }^{(16) .}$

\section{O contexto familiar e social num sofrimento crônico}

Essa categoria evidencia como a doença transforma o contexto familiar e social num sofrimento crônico. A 
possibilidade de o indivíduo perceber o apoio recebido constitui um fator protetor de problemas fisiológicos, psicológicos e sociais, sendo compreendido como um fator preditivo da saúde e da adaptação individual, com possibilidade de melhora da autoestima e do humor, diminuindo o estresse e os sentimentos de solidão e fracasso ${ }^{(28)}$.

M3 evidencia como é difícil permanecer ativa em sua vida social, pois não possui auxílio no cuidado ao filho deficiente:

"E questão social eu não tenho mais, né? Não posso sair pra nenhum canto. Não tem com quem deixar ele. Só fico eu e meu esposo. Fica dificil, só em casa mesmo". (M3)

Emocionada, outra entrevistada menciona o distanciamento dos seus outros filhos e revela, fragilizada, sua maior angústia na sua nova condição de vida:

"Ficar longe da minha família, né? Porque eu nunca passei por isso e agora eu estou passando. Apesar que eu tô cuidando do meu filho, mas também tem o outro lado, né?. (M1)

Outra mãe, 18 anos, vivenciando o sofrimento de seu filho único ser portador de uma patologia neurológica irreversível, narra bastante emocionada a experiência de não possuir apoio familiar:

"Meus pais não estão comigo. Só quem está do meu lado mesmo, até agora, é o meu marido. Meus pais, meus tios não tão nem aí pra mim." (M7)

A participação da família é decisiva para o êxito do processo terapêutico. Entretanto, deve-se considerar que em cada família existem identidades próprias, com diferentes crenças, conceitos e formas de relação. A presença de uma criança portadora de deficiência no meio familiar gera impacto em todos os membros dessa família, resultando em modificações dos papéis e dos relacionamentos ${ }^{(29)}$.

\section{"Aquele aparelho": compreensão acerca da ventilação mecânica}

Essa categoria mostra a compreensão acerca da ventilação mecânica. A nova realidade materna de se deparar com um ambiente repleto de aparelhos desconhecidos, observando o seu filho "naquele aparelho", gera sentimentos de angústia e medo. O entendimento da ventilação mecânica, colocada em uma linguagem coloquial, pode ajudar a mãe a ter uma compreensão maior acerca da melhoria que esse aparelho pode oferecer, evitando fadiga muscular do seu filho através da diminuição do trabalho respiratório e da reexpansão de áreas mal ventiladas dos pulmões ${ }^{(30)}$.
Com certo estranhamento, M2 fala acerca do aparelho de ventilação mecânica:

"Aquele aparelho ali, só entendo que ele é pra ajudar ela a respirar. Ela não consegue, né, mas ela ainda corre o risco muito grande naquele aparelho. Aí o cuidado é maior." (M2)

O cuidado com o "aparelho" faz com que as mães sintam-se inseguras durante a execução de atividades como dar banho ou até mesmo segurar a criança no colo, com receio de machucá-la. Muitas vezes, é necessário o desenvolvimento de novas habilidades, o que requer um novo aprendizado quanto às diversas técnicas de cuidado em saúde ${ }^{(16)}$.

Outra participante revela angústia ao se deparar com o dia a dia da sua filha em suporte ventilatório, e considera as "disfunções psicológicas" como um fator complicador durante o processo de desmame do aparelho:

"O meu modo de pensar [é] que ela não é dependente dele, porque como ela já respirou em ar ambiente uma vez [...], a médica disse pra mim que tem chance de sair do aparelho, né? É só ela ajudar, porque o psicológico dela tá muito abalado. É tanto que ela passou uma semana fora dele, tava bem, bem que só, aí quando ela começa ficar depressiva, né, ai cansa." (M5)

A informação em saúde é uma estratégia distante da experiência cotidiana das mães de crianças dependentes de ventilação mecânica. Há uma lacuna importante entre a explicação dos profissionais e a percepção do receptor daquela mensagem. Os sujeitos não compreendem a linguagem tecnicista dos profissionais de saúde ${ }^{(31)}$, sendo importante adequar a linguagem a algo palpável para a realidade das mulheres em sofrimento pelos seus filhos.

$\mathrm{O}$ avanço tecnológico contribuiu para o desenvolvimento de medicamentos e aparelhos de última geração, aumentando a sobrevida de crianças com estado de saúde frágil. Nesse contexto, no ambiente familiar, e mesmo fora dele, essas crianças necessitam de acompanhamento, por apresentarem algum tipo de dependência crônica. Sendo assim, a parceria com as mães é fundamental, visto que elas assumem o compromisso de assegurar melhor qualidade de vida à criança, seja na busca de conhecimentos acerca das suas patologias, seja na forma de cuidar com dedicação, amor e exclusividade ${ }^{(16)}$.

\section{CONSIDERAÇÕES FINAIS}

As narrativas maternas sobre o cotidiano com seus filhos portadores de necessidades especiais foram repletas de angústia e medo, principalmente em relação ao impacto 
inicial do diagnóstico, à pouca compreensão da linguagem biomédica e aos muitos questionamentos que surgem durante todo o período após o diagnóstico e durante a internação hospitalar. No entanto, após o processo de assimilação da nova realidade e superada a fase de negação da perda simbólica do seu filho perfeitamente saudável, as mães mostram-se empenhadas em lutar pela sobrevivência e pelo bem-estar do filho. As dificuldades percebidas envolvem aspectos relacionados ao abandono familiar, ao distanciamento dos demais filhos em detrimento do cuidado ao filho deficiente, à dificuldade em se relacionar em sociedade e acerca do prognóstico e cuidados com seu filho.

Evidenciou-se que a estadia dessas mães dentro do ambiente hospitalar gera repercussões psicológicas, sentimento de medo e angústia diante da expectativa e da falta de esperança em relação à cura, sabendo que seu filho poderá ir a óbito. O conhecimento dessas fragilidades pelos profissionais de saúde pode favorecer transformações incríveis, gerando um novo "cuidar", mais amplo e humanizado, facilitando a recuperação/reestruturação familiar diante desse novo universo.

\section{REFERÊNCIAS}

1. Forti-Bellani CD, Castilho-Wueinert LV. Desenvolvimento motor típico, desenvolvimento motor atípico e correlações na paralisia cerebral. In: Castilho-Weinert LV, Forti-Bellani CD. Fisioterapia em Neuropediatria. Curitiba: Omnipax; 2011. p. 1-22.

2. Feitosa WFF, Silva MGP, Cunha KJB. Perfil de crianças com atrofia muscular espinhal em uma unidade de terapia intensiva pediátrica. R Interd. 2014;7(1):17382.

3. Sarmento JG. Princípios e práticas de ventilação mecânica em pediatria e neonatologia. São Paulo: Manole; 2011.

4. Matsuno AK. Insuficiência respiratória aguda na criança. Medicina (Ribeirão Preto) 2012;45(2):168-84

5. Paula PB, Lasmar LMLBF, Fonseca MTM, Carvalhais MB, Machado MGR. Fisioterapia respiratória nas doenças neuromusculares. Rev Bras Promoç Saúde. 2010;23(1):92-98.

6. Medeiros JKB. Desmame da ventilação mecânica em pediatria. ASSOBRAFIR Ciência. Londrina. 2011;2(1):57-64.

7. Hanashiro M, Franco AOC, Ferraro AA, Troster EJ. Alternativas de tratamento para pacientes pediátricos em ventilação mecânica crônica. J Pediatr (Rio J.). 2011;87(2):145-9.
8. Molina RCM, Higarashi IH, Marcon SS. Importância atribuida à rede de suporte social por mães com filhos em unidade intensiva. Esc Anna Nery Rev Enferm. 2014;18(1):60-67.

9. Vargas RM, Maldonado DM, Scheeren MC, Brazuna JM, Spigolon MFM, Maldonado MJM, et al. Resiliência Familiar no Contexto da Encefalopatia Crônica Infantil. Ensaios Cienc Cienc Biol Agrar Saúde. 2014;18(3):131-5.

10. Rolim KMC, Cruz EMF, Maia LA. A importância do vinculo mãe/filho na atenção humanizada ao recémnascido prematuro: percepção materna. Rev Tend Enferm Profis. 2012;5(1):779-83.

11. Braga PP, Sena RR. Cuidado e diálogo: as interações e a integralidade no cotidiano da assistência neonatal. Rev Rene. 2010;11:142-9.

12. Bardin L. Análise de conteúdo. Lisboa: Edições 70; 2009.

13. Conselho Nacional de Saúde (BR). Resolução $\mathrm{N}^{\circ} 466$ de 12 de dezembro de 2012 - Regulamenta a Resolução N 196/96 acerca das Diretrizes e Normas Regulamentadoras de Pesquisas Envolvendo Seres Humanos [Internet]. 2012 [acesso em 2014 Jan 10]. Disponível em: http://conselho.saude.gov.br/ resolucoes/2012/Reso-466.pdf

14. Sanches LAS, Fiamenghi Jr GA. Relatos maternos sobre o impacto do diagnóstico da deficiência dos filhos. Cad Saúde Colet. 2011;19(3):366-74.

15. Silva CCB, Ramos LZ. Reações dos familiares frente à descoberta da deficiência dos filhos. Cad Ter Ocup UFSCar. 2014;22(1):15-23.

16. Costa ECL, Veloso RA, Feitosa JJM. Crianças portadoras de hidrocefalia: dificuldades e vivência das mães. Rev Interd. 2013;6(1):71-9.

17. Véras RM, Vieira JMF, Morais FRR. A maternidade prematura: o suporte emocional através da fé e religiosidade. Psicol Estud. 2010;15(2):325-32

18. Cunha AMFV, Blascovi-Assis SM, Fiamenghi Jr GA. Impacto da notícia da síndrome de Down para os pais: histórias de vida. Ciênc Saúde Coletiva. 2010;15(2):444-51.

19. Ferrari S, Zaher VL, Gonçalves MJ. O nascimento de um bebê prematuro ou deficiente: questões de bioética na comunicação do diagnóstico. Psicol USP. 2010;21(4)781-808.

20. Cavalcante MMB, Oliveira EN, Costa AA, Ximenes Neto FRG, Chagas MIO, Vasconcelos G. Contribuições 
da Antropologia na Área da Saúde no Brasil: Revisão Sistemática. Cadernos ESP. 2013;7(1):38-47.

21. Diógenes KCBM, Nations M. "Prismas de percepção": múltiplas leituras das campanhas em saúde no Nordeste brasileiro. Cad Saúde Pública. 2011;27(12):2469-73.

22. Gomes AMA, Nations MK, Sampaio JJC. Cuidar e ser cuidado: relação terapêutica interativa profissionalpaciente na humanização da saúde. Rev Aps. 2011;14(4):435-46.

23. Araújo LC, Pagnan LB, Zanetti LR, Simões JC. A arte de ouvir o paciente. Rev Med Resid. 2011;13(3):200-5.

24. Barbosa DC, Sousa FGM, Silva ACO, Silva IR, Silva DCM, Silva TP. Funcionalidade de famílias de mães cuidadoras de filhos com condições crônicas. Ciênc Cuid Saúde. 2011;10(4):731-8

25. Gomes ILV, Caetano R, Jorge MSB. Compreensão das mães sobre a produção do cuidado pela equipe de saúde de um hospital infantil. Rev Bras Enferm. 2010;6(3):184-90.

26. Carmona EV, Coca KP, Vale IN, Abrão AFV. Conflito no desempenho do papel de mãe em estudos com mães de recém-nascidos hospitalizados: revisão integrativa. Rev Esc Enferm USP. 2012;46(2):505-12.

27. Alves EF. Qualidade de vida do cuidador de enfermagem e sua relação com o cuidar. Rev Bras Promoç Saúde. 2013;26(1):36-44.

28. Gomes GC, Pintanel AC, Strasburg AC, Erdmann AL. O apoio social ao familiar cuidador durante a internação hospitalar da criança. Rev Enferm UERJ. 2011;19(1):64-9.
29. Schmidt KT, Sassá AH, Veronez M, Higarashi IH, Marcon SS. A primeira visita ao filho internado na unidade de terapia intensiva neonatal: percepção dos pais. Esc Anna Nery Rev Enferm. 2012;16(1):73-81.

30. Perlin DA, Oliveira SM, Gomes GC. A criança na unidade de terapia intensiva neonatal: impacto da primeira visita da mãe. Rev Gaúch Enferm. 2011;32(3):458-64.

31. Diógenes KCBM. Crítica cultural das campanhas de comunicação social em saúde no contexto da pobreza [dissertação]. Fortaleza: Universidade de Fortaleza; 2010.

\section{Endereço do primeiro autor:}

Aline Cabral Cristino

Universidade de Fortaleza - UNIFOR

Av. Washington Soares, 1321

Bairro: Edson Queiroz

CEP 60.811-905 - Fortaleza - CE - Brasil

E-mail: alinecabralc@hotmail.com

\section{Endereço para correspondência:}

Kátia Castelo Branco Machado Diógenes

Universidade de Fortaleza - UNIFOR

Av. Washington Soares, 1321

Bairro: Edson Queiroz

CEP 60.811-905 - Fortaleza - CE - Brasil

E-mail: katiamachadofisioterapia@hotmail.com 